\title{
A Study on Electrical Power for Multiple Linear Wave Energy Converter Considering the Interaction Effect
}

\author{
Qiao Li * ${ }^{-}$, Motohiko Murai ${ }^{-}$and Syu Kuwada \\ Department of Environment and System Sciences, Yokohama National University, Yokohama, \\ Kanagawa 240-8501, Japan; murai-motohiko-pz@ynu.ac.jp (M.M.); kuwada-shu@jmuc.co.jp (S.K.) \\ * Correspondence: liqiao23@hotmail.com
}

Received: 20 September 2018 ; Accepted: 26 October 2018; Published: 1 November 2018

check for updates

\begin{abstract}
A linear electrical generator can be used on wave energy converter for converting the kinetic energy of a floating structure to the electricity. A wave farm consists of multiple wave energy converters which equipped in a sea area. In the present paper, a numerical model is proposed considering not only the interference effect in the multiple floating structures, but also the controlling force of each linear electrical generator. In particular, the copper losses in the electrical generator is taken into account, when the electrical power is computed. In a case study, the heaving motions and electrical powers of the multiple wave energy converters are estimated in the straight arrangement and triangle arrangement. In addition, the average electrical power is analyzed in different distances of the floating structures. The aim of this paper is to clear the relationship between the interference effect and electric powers from wave energy converters. This will be useful for deciding the arrangement of multiple wave energy converters.
\end{abstract}

Keywords: wave energy converter; interaction effect; array condition

\section{Introduction}

Converting wave energy to electricity from ocean waves is one of the greatest attractions in ocean engineering. Till date, many different concepts have been proposed with the goal to convert the kinetic and potential energy of ocean waves [1,2]. Some significant types are given as follows: oscillating water column (OWC), over-topping device, hinged multi-module converter, point absorber etc. OWC is proposed based on the principle of wave induced air pressurization. Rezanejad, K. et al. [3] investigated the hydrodynamic performance of an OWC wave energy device using boundary integral equation method (BIEM) simulation and small scale model experiment. Viviano A. [4] discussed the scale effects of OWC by a small scale and a similar large scale device. Additionally, the feasibility study for a green touristic infrastructure by the installation of an OWC system in the port of Giardini Naxos [5]. An over-topping device captures sea water of incident waves in a reservoir above the sea level, then releases the water back to sea through turbines. An example of such a device is the Wave Dragon [6]. A hinged multi-module converter is made up of connected sections which flex and bend as waves pass, this motion is used to generate electricity. The effect of structural flexibility on the maximum wave energy conversion by two interconnected floaters is investigated [7]. A point absorber is a device that heave up and down on the surface of the water. Because of their small size, wave direction is not important for these devices [1]. A point absorber includes three technical parts: floater system which catches the wave energy, power take-off system and electrical energy generation system [8].

Floater system moves up and down on the water surface converting the wave energy into kinetic energy. Nagulan S. [8] provided the information on front end energy conversion of point absorber type wave energy converters. They indicated that the front end energy converter is the only responsible 
stage to capture as maximum energy as possible from the incoming wave and the natural frequency of the device should match with the wave frequency. Power take-off system converts the kinetic energy into electrical energy, and various control methods have been proposed. Method include resistive loading control (RL) [9], approximate complex-conjugate control (ACC) [10], model-predictive control (MPC) [11] and approximate complex-conjugate control considering generator copper losses (ACL) et al. Jorgen H. [12] and Dan-EI M.A. [13] compared some of these control methods performance by simulation. The experiment study of PTO systems was carried out by T. Taniguchi [14]. In his research, the motion of floating structure and electrical powers by different control systems have been investigated. Electrical energy system can be divided into linear generation, rotary generation and electro active polymer. Most of the PTO systems produce mechanical rotation but a few of them produce linear motion to energize linear generators [8]. Apart from these active control methods, nonlinear power capture mechanism such as bistable mechanism [15], tristable mechanism [16], snap through PTO system [17], negative stiffness [18] has also been researched as a hot spot in the recent years. These nonlinear power capture mechanism will assist the efficiency of the energy converter.

On the other hand, a wave farm includes multiple wave energy converters in a certain configuration. By using multiple wave energy converters, the wave conditions of them are varied because of the interference effect. The interaction phenomena is that the scattering waves from a floating body induces to the others. So, the interaction of waves effects to both in diffraction and radiation problem of the floating body. This means that the interference affects the performance of the effect generated electricity by the multiple WECs. In addition, the amount of the degree of the effect is changed by wave period and an arrangement of WECs. Several numerical methods have been proposed to analyze the response of arrays of wave energy converters to the incident wave climate and the resulting modification of wave conditions, particularly down-wave of such arrays [19]. Reviews of available modelling approaches and their applications are discussed in [20,21]. B. Borgarino [22] assessed the influence of distances between generic point-absorber WECs, and cleared that the electrical power increased in some distance compare to single one because of interference effects. His models include 9-25 cylinders arranged in squares, all of them have the same PTO characteristics. The experimental arrangement and the obtained database are presented by Vasiliki S. et al. [23]. They focus on the wave height in the arrangement.

In the present study, a point absorber WEC with a linear generator which proposed by "Linear-driving type Wave Energy Converter Project" of NEDO Japan is assumed. A numerical model is proposed to calculate the electrical power, considering both the controlling force and the interference effect in multiple floating structures. Especially, the copper loss in the linear electrical generator is taken into account. In the numerical model, the Three-dimensional Singularity Distribution Method (3D-SDM) and the dynamic equation of motions with controlling force are used. At first, the diffraction and radiation wave exciting forces from itself and other floating structures are calculated by 3D-SDM respectively. In addition, then, the motions of each floating structure are computed by the dynamic simultaneous equations of motions, here, the same and different PTO characteristics of each WEC will be discussed. Finally, the electrical power is computed by an absorbed power apart from a copper loss.

In past studies [22-24], the controlling force of each WEC in arrangement are the same to it in single condition. Thus, the interference effect is only considered in the transformation of wave energy to the motion of floating bodies, but the conversion from the motion to electric power is not optimized. In this simulation, each WEC in arrangement could be controlled in different controlling force following its position and wave condition. The total electric power of all WECs in arrangement will be discussed as an evaluation parameter. As an example of the proposed numerical model results, the electrical powers of the single model and three models in arrangement condition will be compared. In this paper, not only do we discuss the electrical powers, but we consider the controlling force coefficients, the heaving motions and absorbed powers as well.

We can take advantage of the numerical model to estimate the heaving motion and the expected electrical power of each wave energy converter in different relative positions and different controlling 
force. It can be used to find the best distance and relative position between floating structures. On the other hand, it can help us decide the range of controlling force in the design of the control system. The electrical power result computed by the present numerical model is an expected value, which is a target value that can be used to estimate different controlling methods.

\section{Formulation and Solution Method}

\subsection{Hydrodynamic Forces}

Three-dimensional Singularity Distribution Method (SDM) is a general method for analysis of hydrodynamic forces on offshore structure. The methodology of the SDM was introduced by W.D.Kim [25] and Garrison [26], and it has since been successfully applied to a variety of shapes by Faltinsen et al. [27], Oortmersen [28].

All the motions of floating body are assumed to be sinusoidal in time with circular frequency $\omega$, and the velocity potential of the first-order incident wave progressing to $x$ positive direction is expressed in the form

$$
\Phi(x, y, z, t)=\operatorname{Re}\left[\phi(x, y, z) e^{-\mathrm{i} \omega t}\right]
$$

The velocity potential which satisfies the governing equation and linearized boundary conditions, is summarized as follows:

$$
\begin{aligned}
& \text { [L] } \begin{array}{ll}
\nabla^{2} \phi=0 & \text { for } z \leq 0 \\
\text { [F] } \quad \frac{\partial \phi}{\partial z}-K \phi=0 & \text { on } z=0
\end{array} \\
& \text { [B] } \quad \begin{array}{ll}
\frac{\partial \phi}{\partial z}=0 & \text { as } z=-h
\end{array} \\
& \text { [H] } \begin{cases}\frac{\partial \phi_{D}}{\partial n}=0 & \text { on } S_{H} \\
\frac{\partial \phi}{\partial n}=\dot{\xi}_{a} n & \end{cases}
\end{aligned}
$$

Here, $n$ is the normal vector and $\xi_{a}$ denotes the amplitude of incident wave. (2) is the Laplace equation in the fluid domain; (3) is the linear free-surface condition $\left(K=\omega^{2} / g\right)$; (4) is a condition on the sea bottom and (5) is the conditions on the wetted body surface $S_{H}$. The diffraction potential $\phi_{D}$ in (5) is defined as the sum of the incident-wave potential $\phi_{0}$ plus the scattering potential $\phi_{d}$.

The velocity potentials which satisfy these boundary conditions can be calculated by free-surface Green function $G(P ; Q)$ as

$$
\phi(P)=\iint_{S_{H}} \sigma(Q) \cdot G(P ; Q) d s
$$

where $P=(x, y, z)$ is the field point, $Q\left(x^{\prime}, y^{\prime}, z^{\prime}\right)$ is the source point and $\sigma(Q)$ is the source density on the body surface. The Green function has been well studied and various expressions are known, and the source density could been solved by the SDM.

Once the velocity potentials $\phi$ on the body surface are obtained, it is straightforward to compute the radiation and diffraction forces. The radiation force $F_{R}$ can be expressed as follows:

$$
F_{R i, j}=m_{i, j} \ddot{Z}_{j}+N_{i, j} \dot{Z}_{j}
$$

$m_{i j}$ and $N_{i j}$ is added mass and damping coefficient, which are given by 


$$
\begin{gathered}
m_{i j}=-\rho \operatorname{Re}\left[\sum_{m=1}^{N} \phi_{j m} \cdot n_{i m} \cdot S_{m}\right] \quad(i, j=1 \sim J) \\
N_{i j}=-\rho \omega \operatorname{Im}\left[\sum_{m=1}^{N} \phi_{j m} \cdot n_{i m} \cdot S_{m}\right] \quad(i, j=1 \sim J)
\end{gathered}
$$

$i, j$ in the $F_{R i, j}, m_{i j}$ and $N_{i j}$ is defined the coefficient of $i$-mode which is influenced by $j$-mode. $n_{i m}$ is the $i$-mode normal vector on $m$-th mesh, $S_{m}$ is the mesh area of $m$-th. The floating bodies at wave move in 6 modes of motion: surge, sway, heave, roll, pitch and yaw, the mode numbers ( $i$ and $j$ ) are changed from 1 to 6 respectively, if the body number is one. $J$ denotes the 6 modes times body number. For example, $i$ or $j=3$ is the heave motion of 1 st body, 7 is the surge motion of 2 nd body and 9 is the heave of 2 nd body.

Using the incident wave amplitude $\left(\xi_{a}\right)$, the diffraction force can be expressed as follows:

$$
F_{D i}=f_{D i} \xi_{a}
$$

Here, the $f_{D i}$ defined is the diffraction force coefficient as follows:

$$
f_{D i}=\mathrm{i} \omega \rho \sum_{m=1}^{N}\left(\phi_{0 m}+\phi_{d m}\right) n_{i m} S_{m}
$$

As a result, the coefficient of added mass, damping coefficient and diffraction force coefficient are established by the velocity potentials which are computed by SDM and can be applied to calculate the radiation and diffraction force.

\subsection{Hydrodynamic Model of Multiple Floating Bodies}

It is assumed that there are $N$ floating bodies in array condition. All floating bodies can only move in the heaving motion $(i=3,9 \cdots 3+(N-1) \times 6)$ in Equations (7) and (10), the other degrees of freedom ideally restricting. Denoting the mass matrix and heaving acceleration of the $n$-th body with $M_{n}$ and $\ddot{Z}_{n}$, and using (7) and (10) for the radiation and diffraction forces on the $n$-th body, the dynamic equation which describes the $n$-th floating body motion with a single degree of freedom in the time domain, oscillating in heave is:

$$
M_{n} \ddot{Z}_{n}(t)=F_{D_{n}}(t)+\sum_{n^{\prime}=1}^{N} F_{R_{n n^{\prime}}}(t)+F_{S_{n}}(t)+F_{g_{n}}(t)
$$

The aim of this article is to estimate the expected electrical power of wave energy converters. Therefore, the model in the frequency domain $\omega$ is used. Thus, Equation (12) results are adjusted applying the Fourier Transform as below:

$$
M_{n} \ddot{Z}_{n}(\omega)=F_{D_{n}}(\omega)+\sum_{n^{\prime}=1}^{N} F_{R_{n n^{\prime}}}(\omega)+F_{S_{n}}(\omega)+F_{g_{n}}(\omega)
$$

where $F_{D_{n}}(\omega)$ is the wave diffraction force which is the sum of pressure forces on $n$-th body surface due to incident and diffracted waves. It can be written as follows:

$$
F_{D_{n}}=-\mathrm{i} \omega \rho \iint_{S H_{n}}\left(\phi_{0}+\phi_{d}\right) n_{(3, n)} d S \xi_{a}
$$

$F_{R n n^{\prime}}(\omega)$ is the wave radiation force of $n$-th body in the heaving motion due to the radiated wave when the $n^{\prime}$-th body moves, and can be obtained as follows:

$$
F_{R n n^{\prime}}=-\mathrm{i} \omega \rho \iint_{S H_{n}} \phi_{\left(3, n^{\prime}\right)} n_{(3, n)} d S \dot{Z}_{n^{\prime}}
$$


Here, $\xi_{a}$ is the amplitude of incident wave; $\dot{Z}_{n^{\prime}}$ means the speed of $n^{\prime}$-th body and $S H_{n}$ is the mesh number of $n$-th body. Assuming the inviscid and incompressible flow, the velocity potential $\phi$ is introduced. $\phi_{\left(3, n^{\prime}\right)}$ means the heaving radiation velocity potential in $n^{\prime}$-th body; $\phi_{0}$ is the incident-wave potential and $\phi_{d}$ is the scattering potential from $n$-th body. The velocity potentials are calculated by the Three-dimensional Singularity Distribution Method (3D-SDM) in the study. The normal vector $n$ is defined as positive when directing into the fluid from the body surface, $n_{(3, n)}$ denotes the normal vector of $n$-th body in heave direction.

$F_{S_{n}}$ is the restoring force, which is written as:

$$
F_{S_{n}}=-\rho g A_{w_{n}} Z_{n}
$$

where, $A_{w_{n}}$ and $Z_{n}$ is the water-plane area and heaving motion of $n$-th body; $g$ is the gravitational acceleration.

$F_{g_{n}}$ is the controlling force provided by the linear generator, which can be derived as

$$
F_{g_{n}}=C_{g_{n}} \dot{Z}_{n}+K_{g_{n}} Z_{n}
$$

Here, $C_{g_{n}}$ and $K_{g_{n}}$ are the coefficients for heaving velocity $\dot{Z}_{n}$ and heaving motion $Z_{n}$ respectively, which could be produced by linear wave energy converter.

Using Euler's formula in complex number, heaving velocity $\dot{Z}_{n}$ and heaving acceleration $\ddot{Z}_{n}$ can be expressed as heaving motion

$$
\begin{gathered}
Z_{n}=z_{n} \dot{e}^{-\mathrm{i} \omega t} \\
Z_{n}=-\mathrm{i} \omega z_{n} \cdot e^{-\mathrm{i} \omega t}=-\mathrm{i} \omega Z_{n} \\
\ddot{Z}_{n}=-\omega^{2} z_{n} \cdot e^{-\mathrm{i} \omega t}=-\omega^{2} Z_{n}
\end{gathered}
$$

As a result, the heaving motion $Z_{n}$ of floating structures may be calculated by the dynamic equations of motions which are written as:

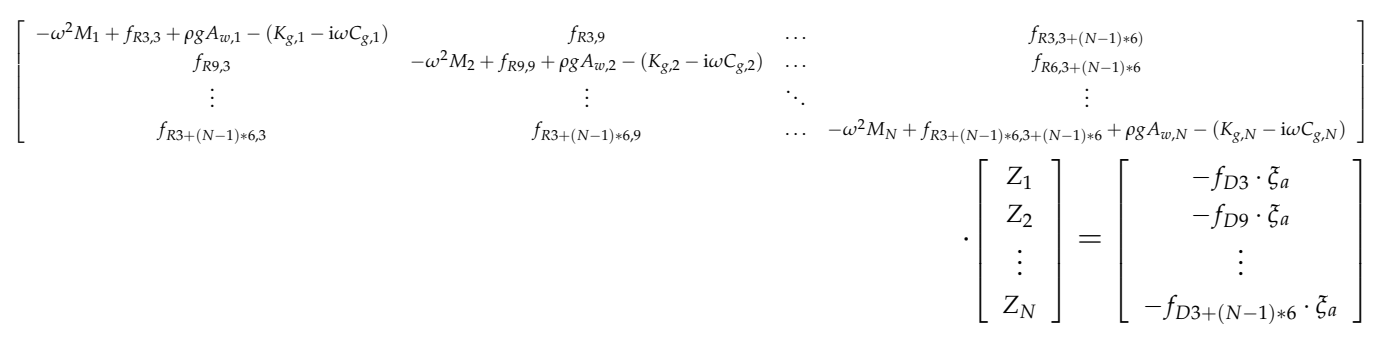

where $f_{R_{n n^{\prime}}}$ and $f_{D_{n}}$ denote as

$$
\begin{aligned}
& f_{D_{n}}=\iint_{S H_{n}}\left(\phi_{0}+\phi_{d}\right) n_{(3, n)} d S \\
& f_{R_{n n^{\prime}}}=\iint_{S H_{n}}\left(\phi_{\left(3, n^{\prime}\right)}\right) n_{(3, n)} d S
\end{aligned}
$$

\subsection{Electric Power}

The mechanism of the wave energy converter in this paper is based on the linear electrical generator system in which the floating body heaves up and down on the water surface and the dynamic energy is converted to electrical energy. There are two parts needed to consider in the energy conversion. One part is the absorbed power from the heave motion of the floating body, which is determined as:

$$
P_{n}=F_{g_{n}} \times \dot{Z}_{n}
$$


The other part is the copper loss in the electrical generator, which can be written as follows:

$$
P_{C_{n}}=R \times\left(F_{g_{n}} / K_{t}\right)^{2}
$$

The copper loss is generated by heat produced in the linear electrical generator and decided by controlling force $\left(F_{g}\right), R$ and $K_{t} . R$ and $K_{t}$ are winding resistance and force constant of linear electrical generator, which decide the performance of the linear electrical generator. In present study, we the assume that $R$ is $0.6 \Omega$ and $K_{t}$ is $90 \mathrm{~N} / \mathrm{A}$ for the model scale, which are the parameters of the linear electrical generator(GLM24-M-2530) made in THK CO., LTD. For the actual scale, $R$ and $K_{t}$ assume $0.3 \Omega$ and $900 \mathrm{~N} / \mathrm{A}$ as reasonable values.

The electrical power is denoted $P_{n}^{\prime}$ given below:

$$
P_{n}^{\prime}=P_{n}-P_{C_{n}}
$$

Then, the absorbed power $\left(P_{n}\right)$ and the copper loss $\left(P_{C_{n}}\right)$ can be integrated in the wave period $T$,

$$
\begin{gathered}
\tilde{P_{n}}=\frac{1}{T} \int_{0}^{T} P_{n} d t=\frac{1}{T} \int_{0}^{T}\left(C_{g_{n}} \dot{Z}_{n}+K_{g_{n}} Z_{n}\right) \dot{Z}_{n} d t=\frac{1}{2} \omega^{2} C_{g_{n}} Z_{n}^{2} \\
\tilde{P_{C_{n}}}=\frac{1}{T} \int_{0}^{T} P_{C_{n}} d t=\frac{1}{T} \frac{R}{K_{t}^{2}} \int_{0}^{T}\left(C_{g_{n}} \dot{Z}_{n}+K_{g_{n}} Z_{n}\right)^{2} d t=\frac{1}{2} \frac{R}{K_{t}^{2}} Z_{n}^{2}\left(\omega^{2} C_{g_{n}}^{2}+K_{g_{n}}^{2}\right) \\
\tilde{P_{n}^{\prime}}=\tilde{P_{n}}-\tilde{P_{C_{n}}}=\frac{1}{2} \omega^{2} C_{g_{n}} Z_{n}^{2}-\frac{1}{2} \frac{R}{K_{t}^{2}} Z_{n}^{2}\left(\omega^{2} C_{g_{n}}^{2}+K_{g_{n}}^{2}\right)
\end{gathered}
$$

which is an expected value within one wave period, and it is named Expected Electrical Power of $n$-th body. This expected value do not consider a specific kind of control strategy, because most classical control strategies can be expressed by controlling force coefficients $C_{g}$ and $K_{g}$, such as the resistive loading control giving without $K_{g}$, the resonance control including $C_{g}$ and $K_{g}$, and approximate complex-conjugate control (ACL control) considering the generator copper losses.

Furthermore, in order to discuss the relationship between interference effect and the electrical power, the average electrical power $\left(\tilde{P_{\text {ave }}}\right)$ of multiple floating bodies are computed as

$$
\tilde{P_{\text {ave }}}=\frac{\sum_{n=1}^{N} \tilde{P_{n}^{\prime}}}{N}
$$

\section{Wave Energy Converter}

\subsection{Linear-Driving Type Wave Energy Converter}

This study is a part of NEDO project which is named "Linear-driving type Wave Energy Converter". A point absorber device is proposed in the project as Figure 1. It generally consists of two separate parts: a spar part which is attached or moored to the seafloor, and a float part which oscillates with the waves. A linear generator is installed in the spar part and the resultant relative motion between two parts is used to generate electricity via a PTO system.

\subsection{Simulation Model}

The image picture and mesh picture of the WEC model is shown in Figure 2. Table 1 shows the principal particulars of the WEC model. The model scale is assumed $1 / 7$ in the simulation in order to support the experiment.

\subsection{Controlling Force Coefficients $C_{g}$ and $K_{g}$ for Single Model}

To make clear the controlling force coefficients $\left(C_{g}\right.$ and $\left.K_{g}\right)$ effect to motion, the heaving motion of single model is calculated in wave period $T$ from $0 \mathrm{~s}$ to $9.0 \mathrm{~s}$. As shown in Figure 3, the resonance period of the floating structure is about $2.0 \mathrm{~s}$ without controlling force, and the Response Amplitude Operator $(R A O)$ reached to 3.73 . 


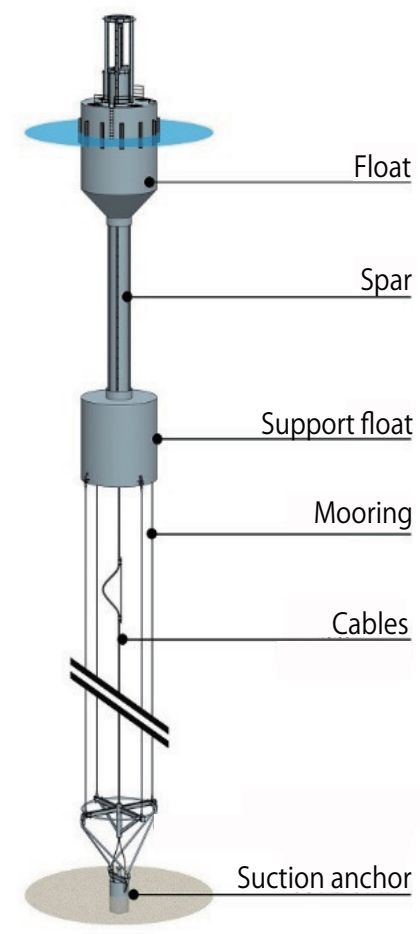

\begin{tabular}{|l|l|}
\hline & \multicolumn{1}{|c|}{ Specification } \\
\hline Performance & $\begin{array}{l}\text { Power generation output : 200kW } \\
\text { Maximum thrust :500kN } \\
\text { Heaving motion limit : } 6 \mathrm{~m}\end{array}$ \\
\hline Float & $\begin{array}{l}\text { Shape : Hollow cylinder } \\
\text { Outside diameter : 7m } \\
\text { Height : } 6 \mathrm{~m} ~ 10 \mathrm{~m}\end{array}$ \\
\hline Spar & $\begin{array}{l}\text { Inside diameter : } 2 \mathrm{~m} \\
\text { Height : } 40\end{array}$ \\
\hline Weight & About 180 ton \\
\hline $\begin{array}{l}\text { Mooring } \\
\text { and Anchor }\end{array}$ & $\begin{array}{l}\text { Mooring : TLP type } \\
\text { Anchor : Suction anchor }\end{array}$ \\
\hline
\end{tabular}

Figure 1. The image of a point absorber wave energy converter proposed in "Linear-driving type Wave Energy Converter Project".
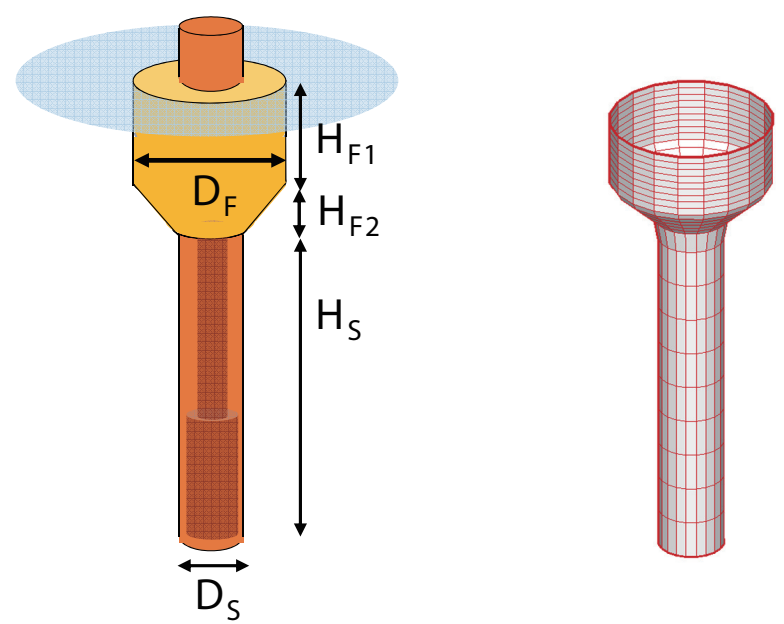

Figure 2. Simulation model.

Table 1. Principal particulars of WEC model.

\begin{tabular}{cccc}
\hline Main Dimensions & Units & Model Scale & Actual Scale \\
\hline Diameter of float $\left(D_{F}\right)$ & $\mathrm{m}$ & 1.00 & 7.00 \\
Height-1 of float $\left(H_{F 1}\right)$ & $\mathrm{m}$ & 0.55 & 3.36 \\
Height-2 of float $\left(H_{F 2}\right)$ & $\mathrm{m}$ & 0.30 & 2.10 \\
Diameter of spar $\left(D_{s}\right)$ & $\mathrm{m}$ & 0.40 & 2.80 \\
Height of spar $\left(H_{s}\right)$ & $\mathrm{m}$ & 2.70 & 17.67 \\
Volume of float $\left(V_{o l}\right)$ & $\mathrm{m}^{3}$ & 0.48 & 99.58 \\
Water area of float $\left(A_{w}\right)$ & $\mathrm{m}^{2}$ & 0.66 & 29.59 \\
\hline
\end{tabular}




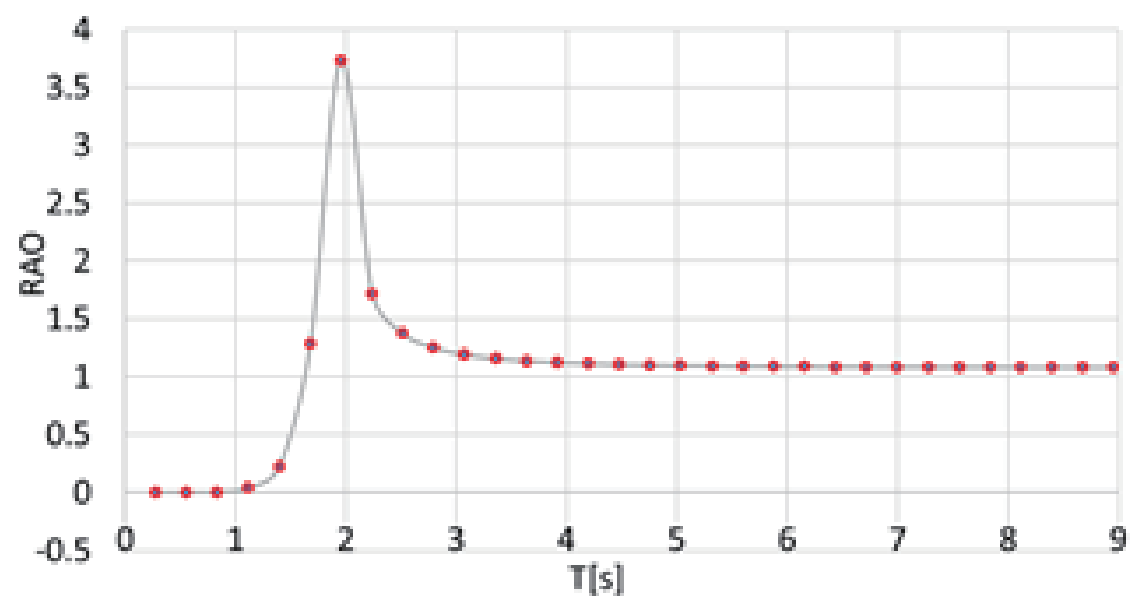

Figure 3. RAO of floating structure.

Next, we kept $K_{g}=0 \mathrm{~N} / \mathrm{m}$ and changed $C_{g}$. Figure 4 shows the results of $R A O$ in different $C_{g}$ for each wave period. As shown in this figure, when the $C_{g}$ in particular range, the $R A O$ increase rapidly in the resonance period and the maximum value is 4.43 , which is bigger than 3.73 (max $R A O$ without controlling force). The resonance frequency could be changed by chose the appropriate $C_{g}$. On the other hand, we kept $C_{g}=0 \mathrm{Ns} / \mathrm{m}$ and changed $K_{g}$. As shown in Figure 5, the $K_{g}$ can be used to change the resonance period of the floating body. By giving large $K_{g}$ acting as reducing the restoring force as shown in Equation (21), the resonance period can be changed to large period, and the $R A O$ became huge. The number of $R A O$ is only a theoretical calculating number, the heaving motion limitation must be decided according to the mechanical structure of wave energy converter. According to the results, it could be understood that the function of control force coefficients $\left(C_{g}\right.$ and $\left.K_{g}\right)$ can change the resonance frequency and resonance period.

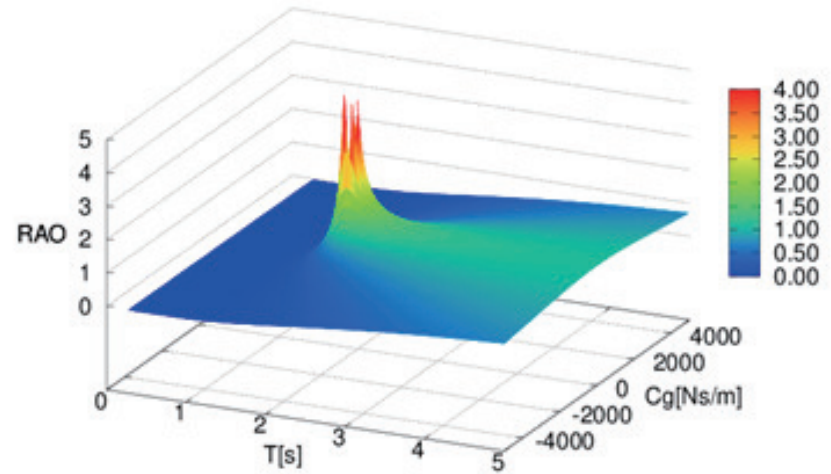

Figure 4. RAO of the floating structure in different $\mathrm{Cg}(\mathrm{Cg}=-5000-5000[\mathrm{Ns} / \mathrm{m}], \mathrm{Kg}=0[\mathrm{~N} / \mathrm{m}])$.

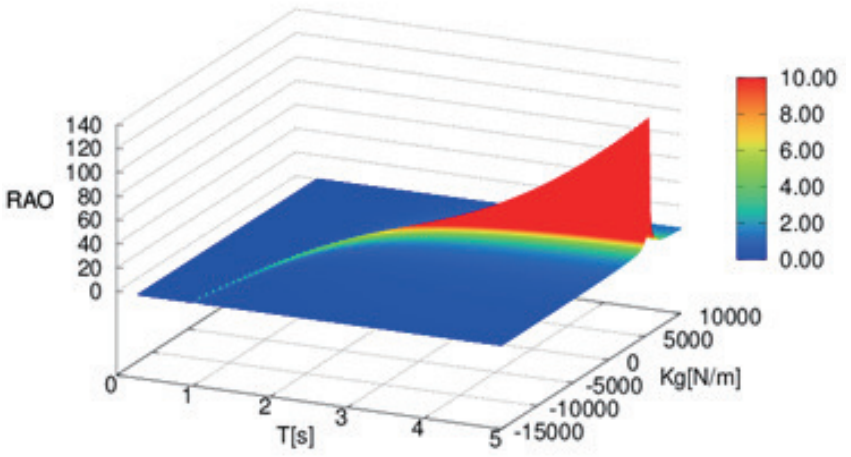

Figure 5. RAO of the floating structure in different $\mathrm{Kg}(\mathrm{Cg}=0[\mathrm{Ns} / \mathrm{m}], \mathrm{Kg}=-15,000-10,000[\mathrm{~N} / \mathrm{m}])$. 


\section{The Results of Multiple WECs in Regular Wave}

The results as the solution method will be shown and discussed in this section. The objective of the present study is shown as follows:

1. How to decide the controlling force to the linear generator in arrangement.

2. The relationship between the interference effect and electric power from WECs.

3. How to decide the arrangement of multiple WECs.

We cover these 3 objects to discuss the simulating results. At first, wave period, wave amplitude and WECs arrangement condition are changed as the parameter in the regular wave. Then, basis on the results in the regular wave, the estimation in the real sea wave condition are proceed. In the study, three kinds of arrangement will be discussed. They are single arrangement, straight arrangement and triangle arrangement as shown in Figure $6 a-c$, respectively. In a case study, three wave energy converter models are used in the straight and triangle arrangement. The limit of the heave motion is decided $0.2 \mathrm{~m}$. As show in Figure 6, the models are set in the head-wave condition. The distances of each models are changed from 1.5 to 8.0 times diameter of the model in the straight and triangle arrangement. The reason of choosing this range of the distance is; the adjacent model may not contact each other in waves and it is not too far to appear clearly the hydrodynamic interaction effect among the models. In the simulation, the wave amplitude changes from 0.01 to $0.15 \mathrm{~m}$, in every $0.01 \mathrm{~m}$, and the wave period is from 0.6 to $5.0 \mathrm{~s}$, in every $0.1 \mathrm{~s}$. The depth of the water is assumed $4.5 \mathrm{~m}$.

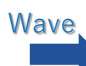

(a) Single condition

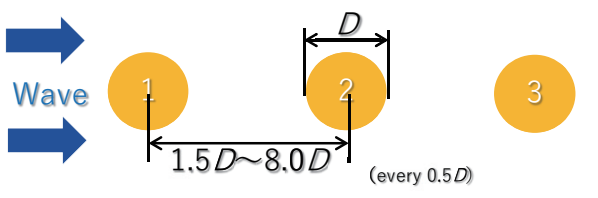

(b) Straight arrangement

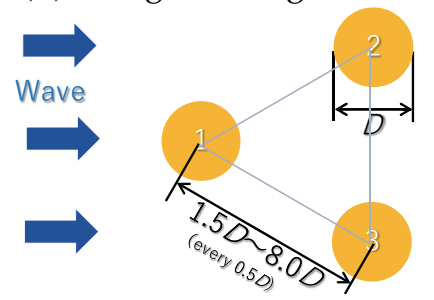

(c) Triangle arrangement

Figure 6. Arrangement of multiple wave energy converters.

\subsection{Investigation of Controlling Force in Arrange Condition}

As the proposed method, the controlling force coefficients $K_{g}$ and $C_{g}$ are changed for wave periods, and the optimal values found by searching $C_{g}$ in 0-2500 [Ns/m] and $K_{g}$ in $-5000-6000[\mathrm{~N} / \mathrm{m}]$ considering the controlling force limitation. We suppose that the controlling force coefficients of each floating body can be controlled commonly and independently. Controlled commonly means the $K_{g}$ and $C_{g}$ are the same in every WEC and decided only in wave condition. On the other hand, controlled independently purports that in addition to wave condition the interference effect are also considered to decide the controlling force coefficients. To compare these two method, we discuss the relationship between the controlling force of each WECs in arrangement and interference effect.

When the total expected electrical power $\left(P_{1}^{\prime}+P_{2}^{\prime}+P_{3}^{\prime}\right)$ became maximum, the results of $K_{g}, C_{g}, Z, P$ and $P^{\prime}$ of each floating body are exported. Figure 7 shows the results of 3 floating bodies in 
controlled commonly. Figure 8 shows the results in controlled independently. In addition, the results of the single body are also shown in the same figure, to compare with the variation. The wave amplitude is $0.1 \mathrm{~m}$ and the distances of each models are 3 times diameter $(3 \mathrm{~m})$ in straight arrangement.

At first, it will be easy to observe the difference of the two ways by comparing the curves of $C_{g}$ in Figures $7 \mathrm{~b}$ and $8 \mathrm{~b}$. It is imagined that this $C_{g}$ 's difference will directly affect the total power generation and the interference effect cannot be ignored in the certain range. We discuss the details of the interference effect by comparing with the two ways through Figures 7 and 8 as follows.

$K_{g}$ of three models in two methods are similar to the single condition, as shown in Figures 7a and 8a. As the introduction in Section 3.3, $K_{g}$ is used to change the resonance period of the floating body, and it is not changed belong to interference effect. However, the $C_{g}$ of 1,2 and 3 bodies in the straight arrangement are different to single's condition, from $1.2 \mathrm{~s}$ to $4.6 \mathrm{~s}$. We can understand that the interference effect in the short and long wave period is not obvious. When the $C_{g}$ controlled independently, heave motion $Z$ of three WECs reach to the limitation, as shown in Figure 8c. On the other hand, when the $C_{g}$ controlled commonly, a part of $Z$ cannot reach to the limitation. Because of the difference of $Z$, the expected electrical power $\left(P^{\prime}\right)$ of each WEC are different. As shown in Figures $7 \mathrm{e}$ and $8 \mathrm{e}$, the generated electric power under controlling independently is better than that used the controlling parameters commonly in the array. Figures $7 \mathrm{~d}$ and $8 \mathrm{~d}$ show the absorbed power, and the copper loss could be calculated by generated electric power differenced absorbed power.

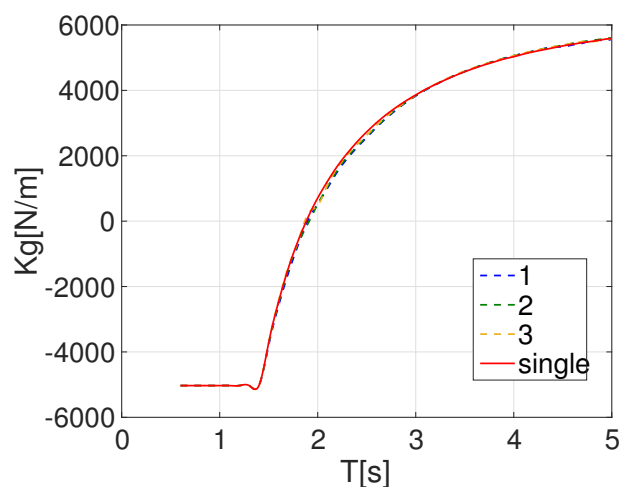

(a)

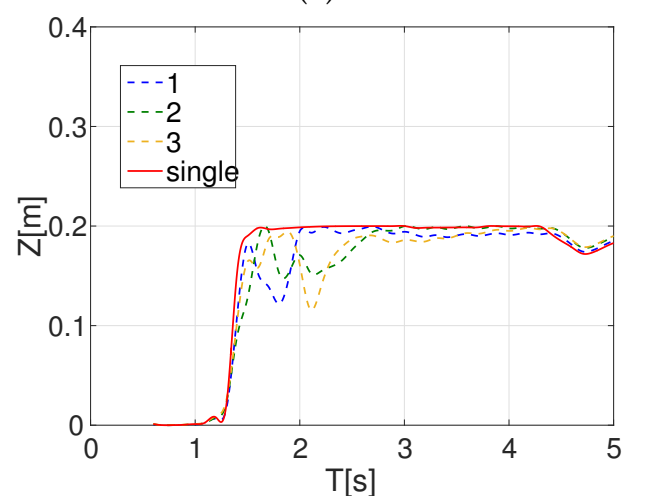

(c)

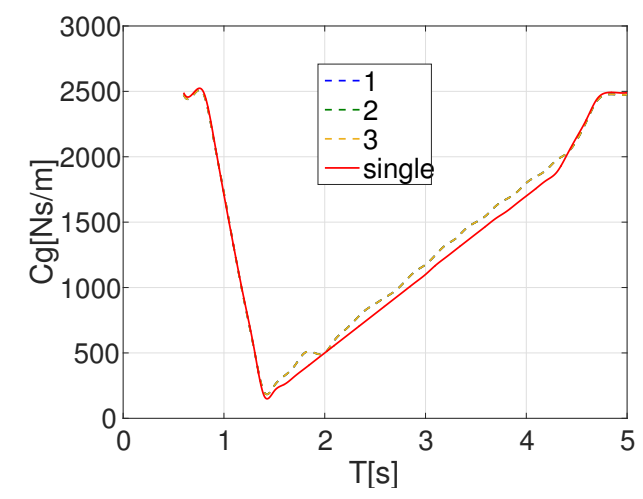

(b)

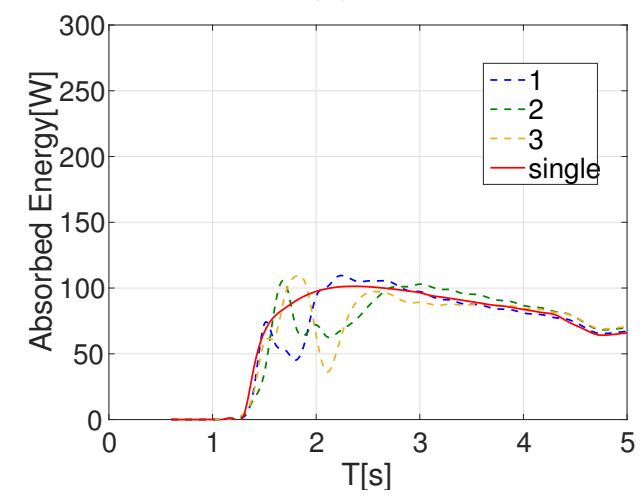

(d)

Figure 7. Cont. 


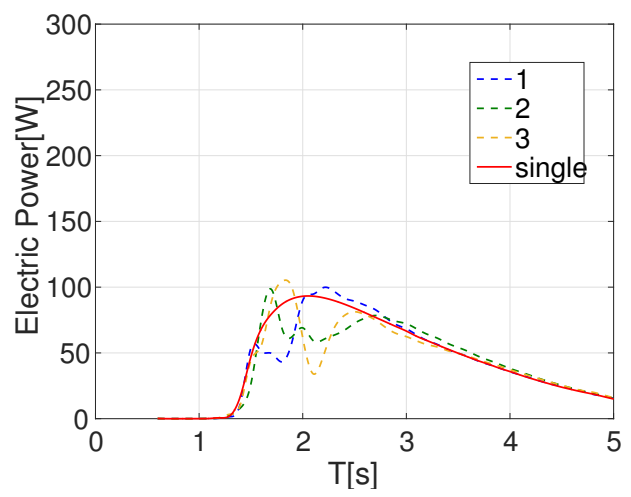

(e)

Figure 7. The results of multiple WECs in regular wave (3.0D, $A m p=0.10[\mathrm{~m}]$, Use common parameters) (a: $K_{g}, \mathbf{b}: C_{g}$, c: heave motion $Z$, d: the absorbed power, e: generated electric power).

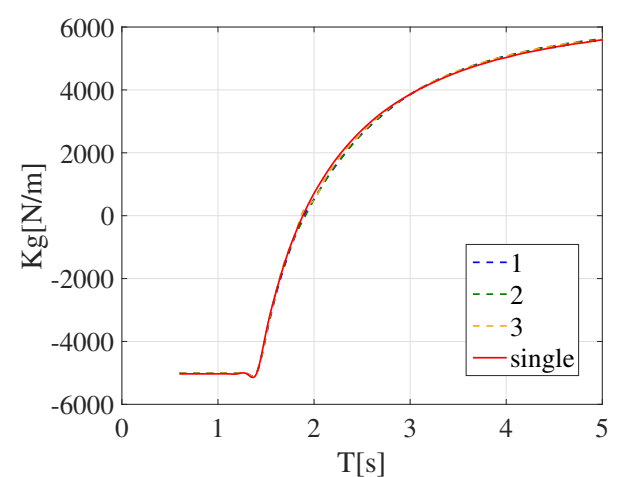

(a)

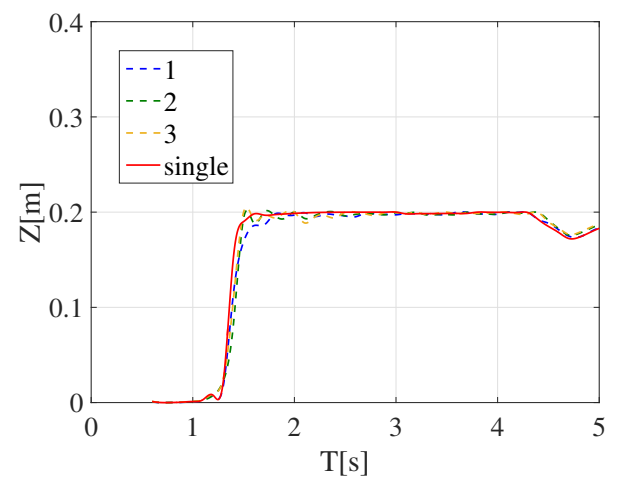

(c)

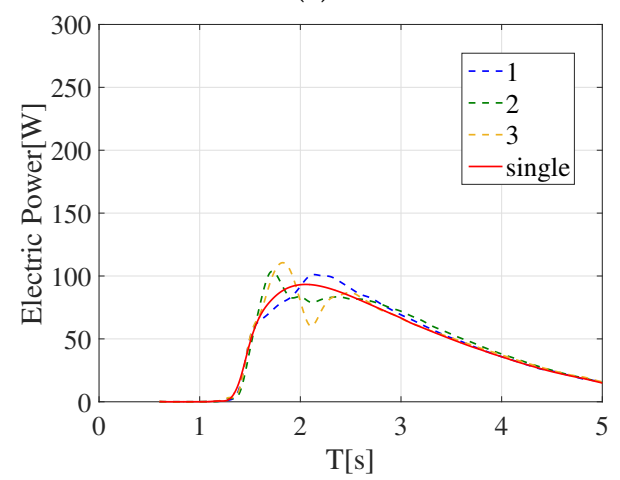

(e)

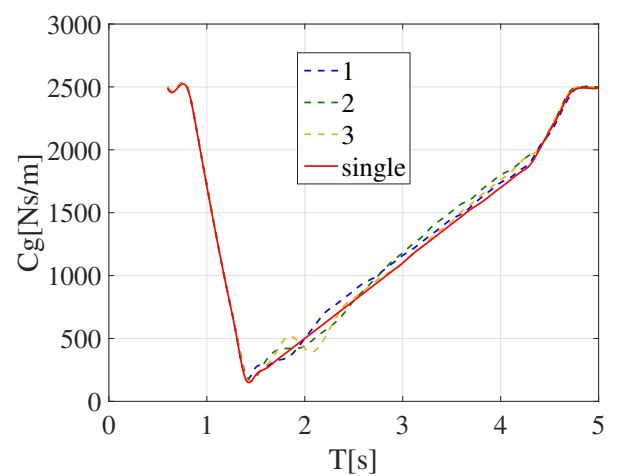

(b)

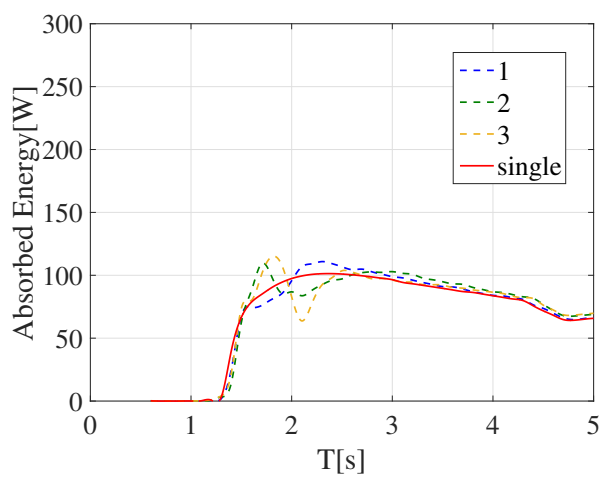

(d)

Figure 8. The results of multiple WECs in regular wave (3.0D, Amp $=0.10[\mathrm{~m}]$, Use independent parameters) (a: $K_{g}, \mathbf{b}: C_{g}, \mathbf{c}$ : heave motion $Z, \mathbf{d}$ : the absorbed power, e: generated electric power). 
Next, in order to compared the electric power results in controlled by the common parameters with in controlled independently much more clearly, the rate of change $E_{\text {ave }}$ are calculated as follows:

$$
E_{\text {ave }}=\frac{\tilde{P}_{\text {ave }}(\text { Controlled independently })}{\tilde{P}_{\text {ave }}(\text { Controlled commonly })}
$$

Figure 9 shows the $E_{\text {ave }}$ as different color, the vertical line shows the distance between the WECs and the horizontal one the wave periods. As shown in this figure, around the resonance period (2.0 s) $E_{\text {ave }}$ is bigger than " 1 ", it is means the average electric power of three WECs in controlled independently is bigger than in controlled commonly. However, in the short and long wave period $E_{\text {ave }}$ is " 1 ".

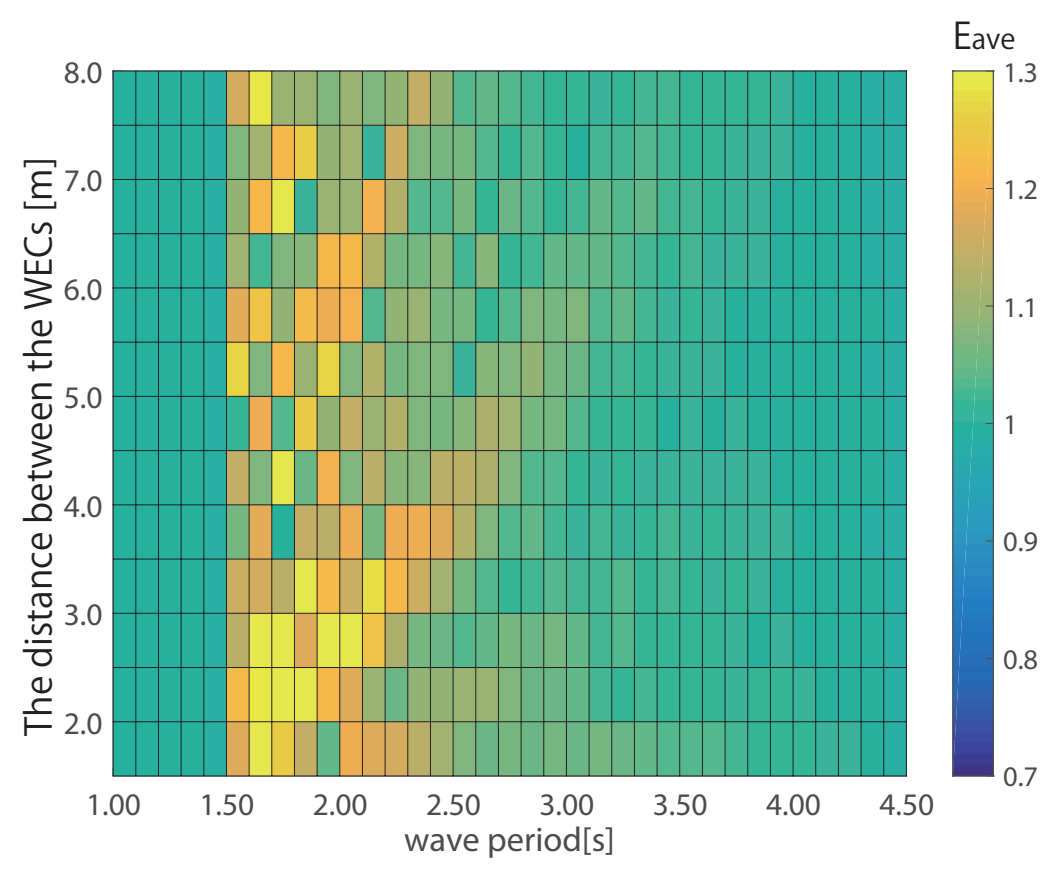

Figure 9. The rate of change of the two methods $E_{\text {ave }}$.

As a result, the $C_{g}$ of each wave energy converter needs change independently following the wave period, especially around the resonance period. In addition, the average electric power in controlled independently is $10-20 \%$ bigger than in controlled commonly. On the other hand, $K_{g}$ in two methods are similar to the single condition, and it is not changed belong to interference effect.

Therefore, the controlling force coefficients of each floating body controlled independently are used in the next calculation.

\subsection{The Influence of Interference Effect to Electric Power}

In preceding section, we cleared how to decide the controlling force of multiple WECs in arrangement. In this section, the electric power is focused on different wave periods, wave amplitude and distance between WECs considering the interference effect. As a case study, the expected electric power of each WECs are calculated in the single condition and in the straight arrangement (the distances of each bodies are $3 \mathrm{~m}$ ). Here, besides the wave period, the wave amplitude is changed from $0.01 \mathrm{~m}$ to $0.15 \mathrm{~m}$ in every $0.01 \mathrm{~m}$. In the calculation of changing wave amplitude, the wave forces are based on linear theory as Section 2.2, and the analysis mechanism of choosing the optimal values of $C_{g}$ and $K_{g}$ is comparison the expected electrical power on all $C_{g}$ and $K_{g}$ to find the best values within the allowable range. Therefore, the best controlling parameters are changed by not only a wave period but also an amplitude of waves. 
Figure 10 shows the distribution map of single floating body in different the wave period and amplitude. $X$-axis shows the wave period, $Y$-axis shows the wave amplitude and $Z$-axis shows the number of electrical power. Moreover, the peak power and its happened period are also shown in the figure. It can be observed that the expected electrical power is increased following the wave amplitude, especially around the resonance period. However, there is no electricity power when the wave period is less than $1.2 \mathrm{~s}$ and the wave period is larger with small wave amplitude.

Figure 11 shows the power distribution map of each floating body when they are in the straight arrangement. The power distribution map and the peak power of each WECs in arrangement is different to the single condition. Therefore, the spacing between two absorbers are relatively small (for this case, $\mathrm{L}=3 \mathrm{D}$ ), the interference effect must be considered when the total electric power of multiple WECs in arrangement are calculated.

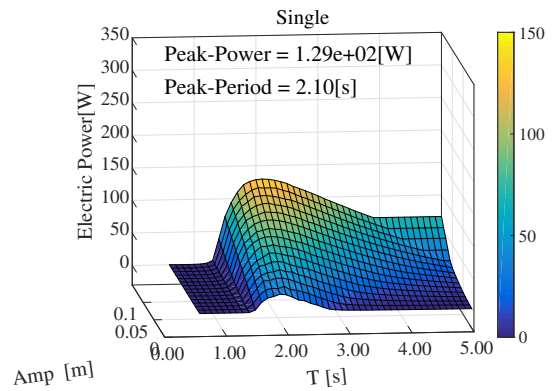

Figure 10. Electric power on single condition in different wave period and amplitude.
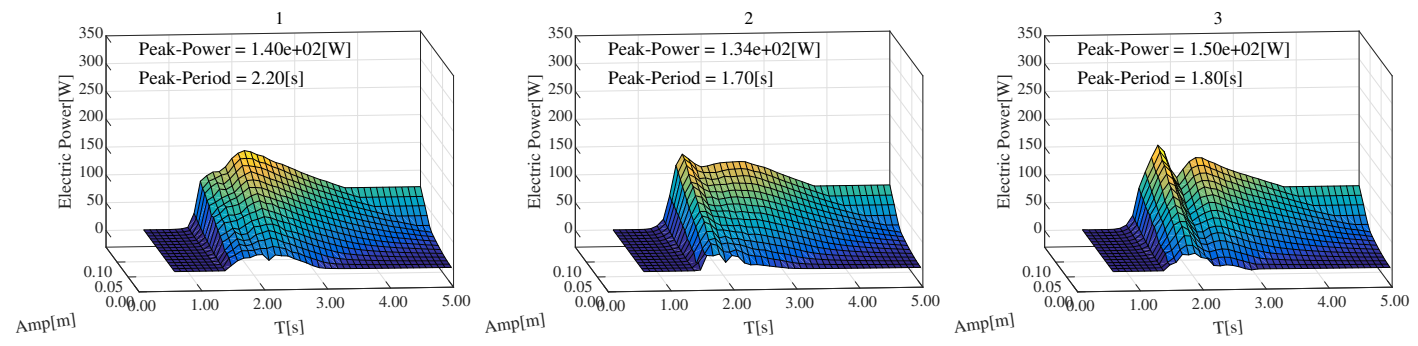

Figure 11. Electric power on straight condition in different wave period and amplitude.

Next, in order to estimate the interference effect, the changing ratio of electric power are defined as follows:

$$
E_{\text {ratio }}=\frac{\tilde{P}_{\text {total }}^{\prime} / N}{\tilde{P}_{\text {single }}^{\prime}}
$$

When the changing ratio of electric power $E_{\text {ratio }}$ greater than " 1 ", the interference effect help the electric power increase. However, the $E_{\text {ratio }}$ is a value which only use for estimating the interference effect, it does not mean that much more electric power can be obtained. Moreover, the triangle arrangement (Figure 6c) will be added to discuss.

The results of $E_{\text {ratio }}$ in different non-dimensional parameter Wave-Length/Diameter $(\lambda / D)$ are show in Figures 12-14. Figure 12 shows the results when the distance between WECs is 1.5D, Figure 13 is $3.0 \mathrm{D}$ and Figure 14 is $5.0 \mathrm{D}$. For comparing the straight arrangement and triangle arrangement, the results in the same distance are shown in the same figure. We can confirm that the changing ratio of expected electrical power is increased and deceased in some area following the wave condition. In addition the increased and deceased area is changed for different distance. Therefore, the positive and negative influence of interference effect could be changed following the wave length (or period) and the distance between WECs. 


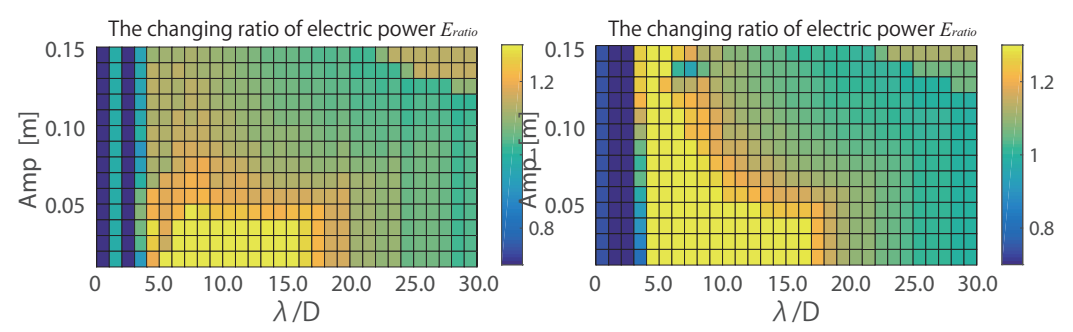

Figure 12. $E_{\text {ratio }}$ in $1.5 \mathrm{D}$ (Left: Straight arrangement; Right: Triangle arrangement).

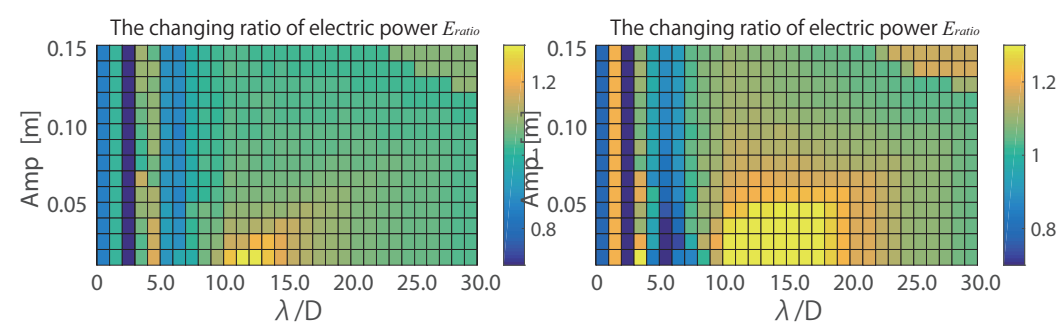

Figure 13. $E_{\text {ratio }}$ in 3.0D (Left: Straight arrangement; Right: Triangle arrangement).

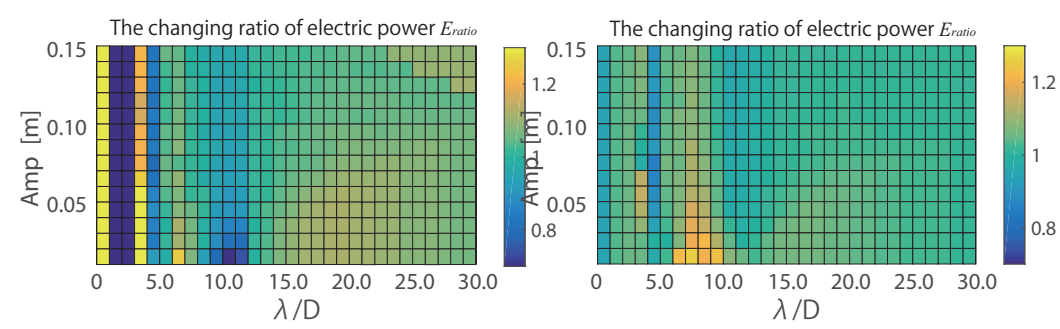

Figure 14. $E_{\text {ratio }}$ in 5.0D (Left: Straight arrangement; Right: Triangle arrangement).

\subsection{Decide the Distance between WECs}

To evaluate the relationship between distance and electrical power, the changing ratio of electrical power $E_{\text {ratio }}$ in straight arrangement and triangle arrangement is calculated to compare with the single one. Here, the distance between the adjacent bodies is changed from $1.5 \mathrm{~m}$ to $8.0 \mathrm{~m}$ every $0.5 \mathrm{~m}$, the Amp kept in $0.1 \mathrm{~m}$.

Figure 15a shows the $E_{\text {ratio }}$ in straight arrangement. The relatively high electrical power performance range is shifted to the longer $\lambda / D$, when the distance becomes longer. The electrical power performance increase more than $10-15 \%$ in some wave condition, in different wave period as the different distance. Figure $15 \mathrm{~b}$ shows the $E_{\text {ratio }}$ in triangle arrangement. The trend is same to straight arrangement. The electrical power performance increment is larger than straight arrangement reached to more than $15 \%$. Therefore, it can be said that the triangle arrangement is better than the straight arrangement for use interference effect in this case.

For showing the relationship between distance and $E_{\text {ratio }}$ clearly, we organize that the vertical line shows the Distance/Wave-Length and the horizontal shows the $E_{\text {ratio }}$, as shown in Figure 16. The $E_{\text {ratio }}$ fluctuate periodically as the Distance/Wave-Length. The peak in the graph means that high average electric power could be obtained by interference effect. Using this figure, the best distance could be choice following the wave condition characteristic of sea area. 


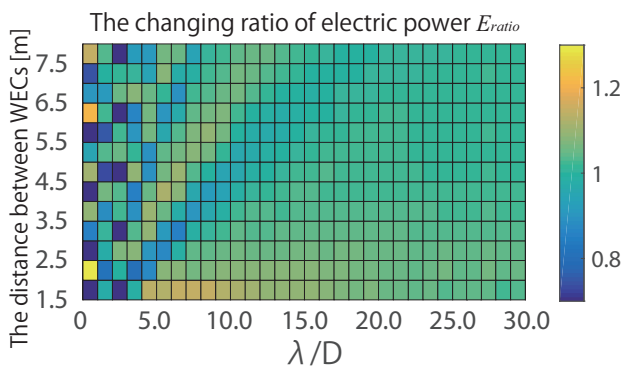

(a)

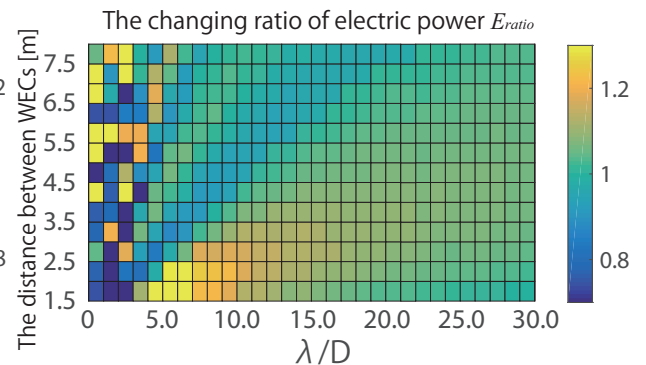

(b)

Figure 15. $E_{\text {ratio }}$ in different distances in $A m p=0.1 \mathrm{~m}$ (Left: Straight arrangement; Right: Triangle arrangement).

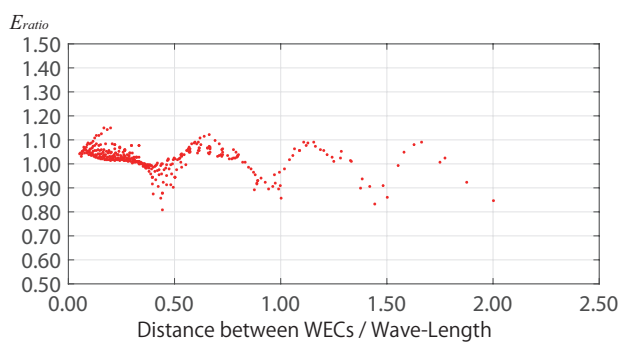

(a)

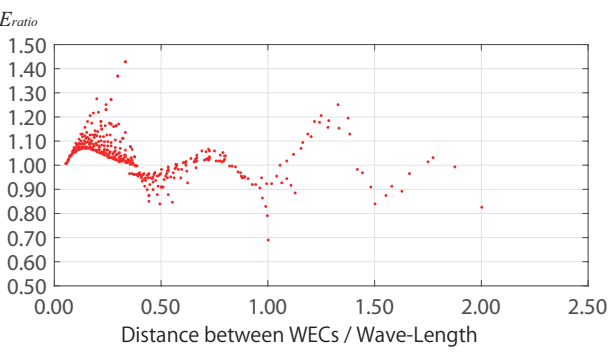

(b)

Figure 16. $E_{\text {ratio }}$ as Distance/Wave-Length in $A m p=0.1 \mathrm{~m}$ (Left: Straight arrangement; Right: Triangle arrangement).

\section{The Electrical Power Estimation of Multiple WECs in Real Sea}

\subsection{Formulation and Solution Method}

We discussed multiple WECs in regular wave. However, a lot of different wave periods and amplitudes are fixed in the real sea, therefore the calculation in the irregular wave is necessary. In this section, the electric power of multiple WECs will be computed in the irregular wave and the interference effect in real sea will be discussed. To predict the response of floating body in the irregular wave, the response spectrum $S_{q q}$ could be calculated by response in regular wave $H(\omega)$ and wave spectrum $S_{Q Q}$ as follows

$$
S_{q q}(\omega)=H(\omega)^{2} \cdot S_{Q Q}(\omega)
$$

which introduced in [29]. Here, the $H(\omega)$ is computed by the electric power divided by significant wave height, JONSWAP (Joint North Sea Wave Observation Project) spectrum [30] are used to show wave spectrum $S_{Q Q}$.

To estimate the electric power in the real sea basic on the $S_{q q}$, the representative value of electric power is denoted $\sigma$ given below:

$$
\sigma=\sqrt{\int_{0}^{\infty} S_{q q}(\omega) d \omega}
$$

Then, in order to discuss the electric power in certain sea area, the electric power distribution are calculated by using the H-T joint probability distribution $P$ (Figure 17), as $P \times \sigma[$ W]. Moreover, the summation of expected electric power in certain sea area could be calculated, which can be written as follows:

$$
P_{\text {Wsea }}=\sum_{i=1}^{I} \sum_{j=1}^{J} P_{i j} \sigma_{i j}
$$


Here, $i, j$ is calculating point of wave period $(i=1 \sim I)$ and wave height $(j=1 \sim J)$, respectively. The representative value of electric power $\sigma$ and the summation of expected electric power $P_{W_{\text {sea }}}$ are used to discuss the WECs performance in the real sea area. Proposed method flow chart in real sea is presented in Figure 18.

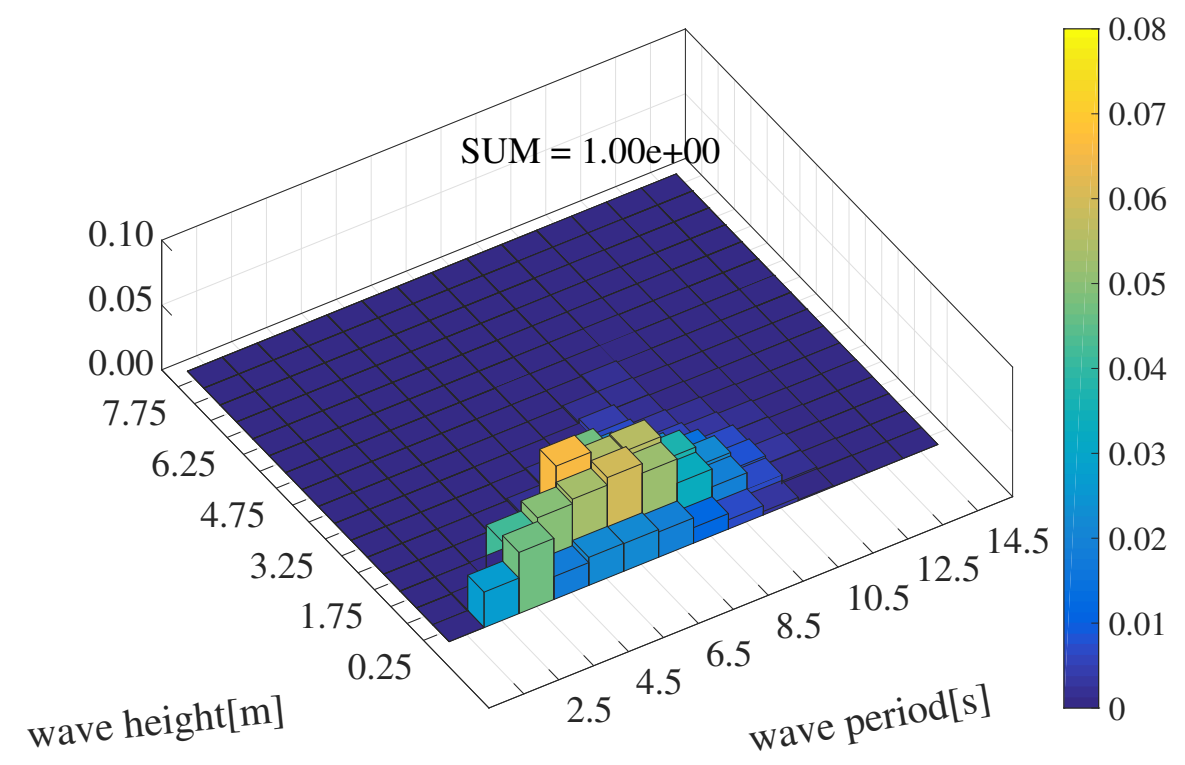

Figure 17. H-T joint probability distribution $P$ in the bay of KAMAISHI.

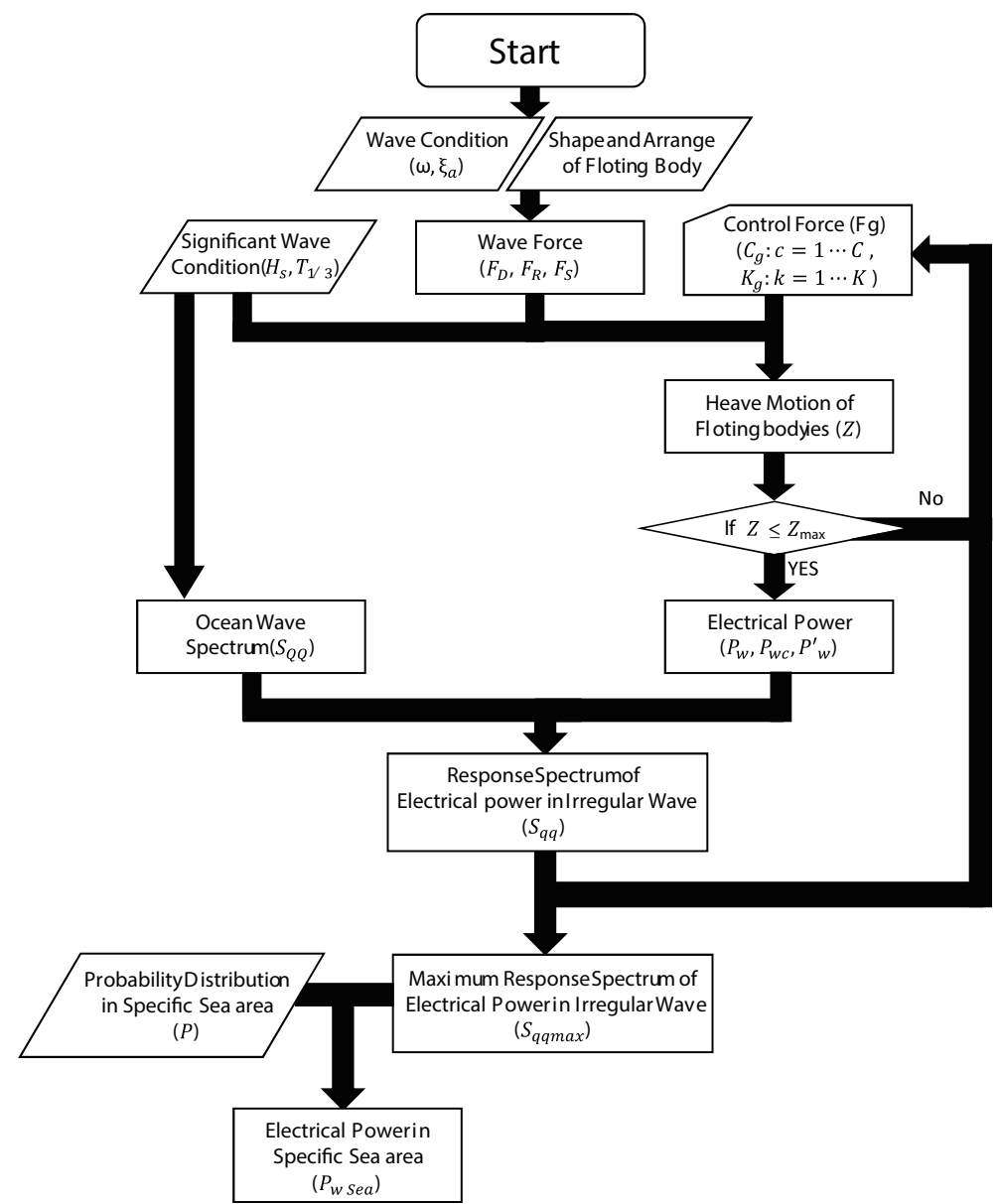

Figure 18. Simulation flow chart in the real sea. 
Actual scale model which set in triangle arrangement and the distance 3.0D, is used in the real sea calculation. As an assumption sea area, the bay of Kamaishi where is located in northeast of Japan are used. The H-T joint probability distribution $P$ of this sea area is shown in Figure 17, which is published in Web [31]. Here, the wave conditions shown by appearing frequency, so the totally frequency in the sea area is 1 . The computational condition in real sea shown as Table 2.

Table 2. Computational condition in real sea.

\begin{tabular}{ccc}
\hline Parameters & Units & Value \\
\hline Wave period $(T)$ & $\mathrm{s}$ & $1.00-18.00$ (every 0.25) \\
Significant wave height $\left(H_{1 / 3}\right)$ & $\mathrm{m}$ & $0.25-7.75$ (every 0.25) \\
Significant period $\left(T_{1 / 3}\right)$ & $\mathrm{s}$ & $1.50-14.50$ (every 1.00) \\
Controlling force coefficient $C_{g}$ & $\mathrm{Ns} / \mathrm{m}$ & $0.000-500,000$ \\
Controlling force coefficient $K_{g}$ & $\mathrm{~N} / \mathrm{m}$ & $-250,000-300,000$ \\
Deep of water $(H)$ & $\mathrm{m}$ & 31.5 \\
Motion limit of floating part $\left(Z_{\text {max }}\right)$ & $\mathrm{m}$ & 2.00 \\
Winding resistance $(R)$ & $\omega$ & 0.3 \\
Force constant $\left(K_{t}\right)$ & $\mathrm{N} / \mathrm{A}$ & 900 \\
\hline
\end{tabular}

\subsection{Compute Result}

Figure 19 shows the result of electrical power distribution in single condition. It can be understood that the electrical power increases following the wave period and amplitude became bigger, because there is much more energy in a large wave's period and large amplitude. Whereas, the result of expected electric power $P_{\text {Wsea }}$ is almost 0 when the wave condition is large wave period and large amplitude. The $P_{W s e a}$ only can be obtained in the high appearing frequency of wave height and wave period.

Figure 20 shows the average result of $3 \mathrm{WEC}$ in triangle arrangement. As the same to single condition, $P_{W s e a}$ only can be obtained in the high appearing frequency of wave H-T. The totally average $P_{\text {Wsea }}$ reach to $221[\mathrm{~kW}], 7 \%$ bigger than 207 [kW] in single condition.

To compare the electric power of WEC in single condition and in arrangement condition from the viewpoint of wave period, Figure 21 shows the distribution map of them. By using the interference effect, the average electrical power in arrange condition increase from wave period $6.5 \mathrm{~s}$, but decrease under $5.5 \mathrm{~s}$ compare with single condition. It could be said that, WECs in appropriately arranged conditions could obtain much more electrical power than single's, and the appropriate arranged conditions must be matched to the wave condition of the installed sea area.
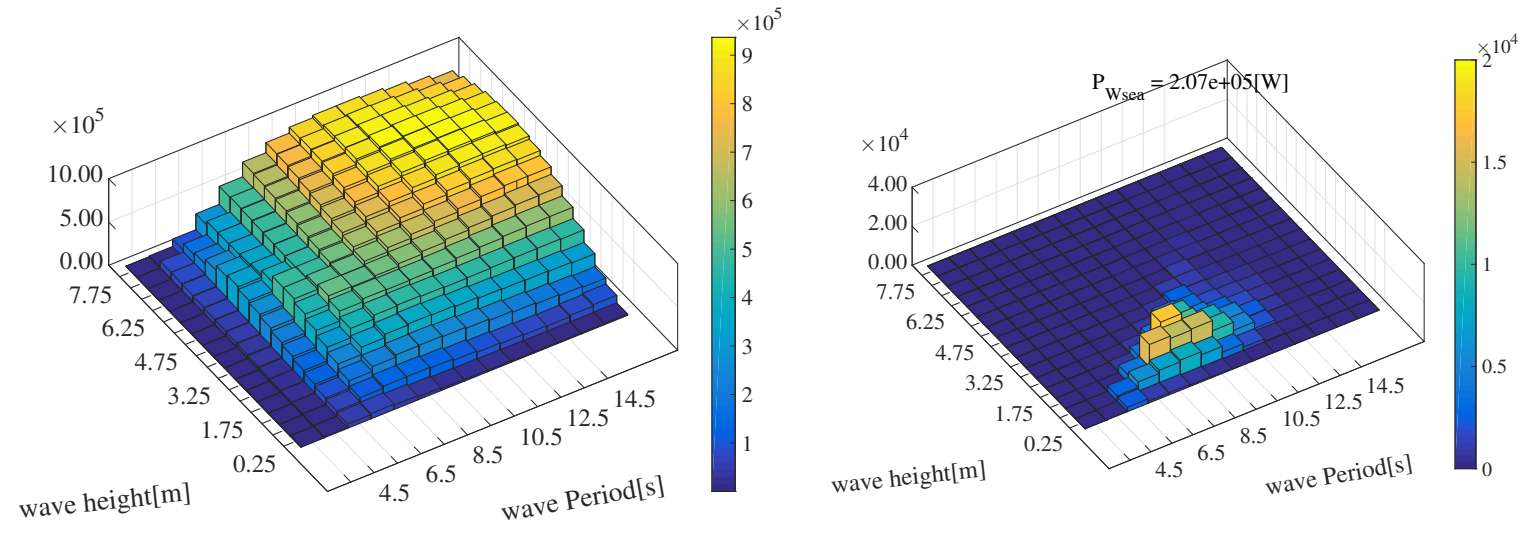

Figure 19. Single condition (Distribution map of electric power $\sigma$ on the left, and distribution map of electric power in a sea area $P \times \sigma$ on the right.) 

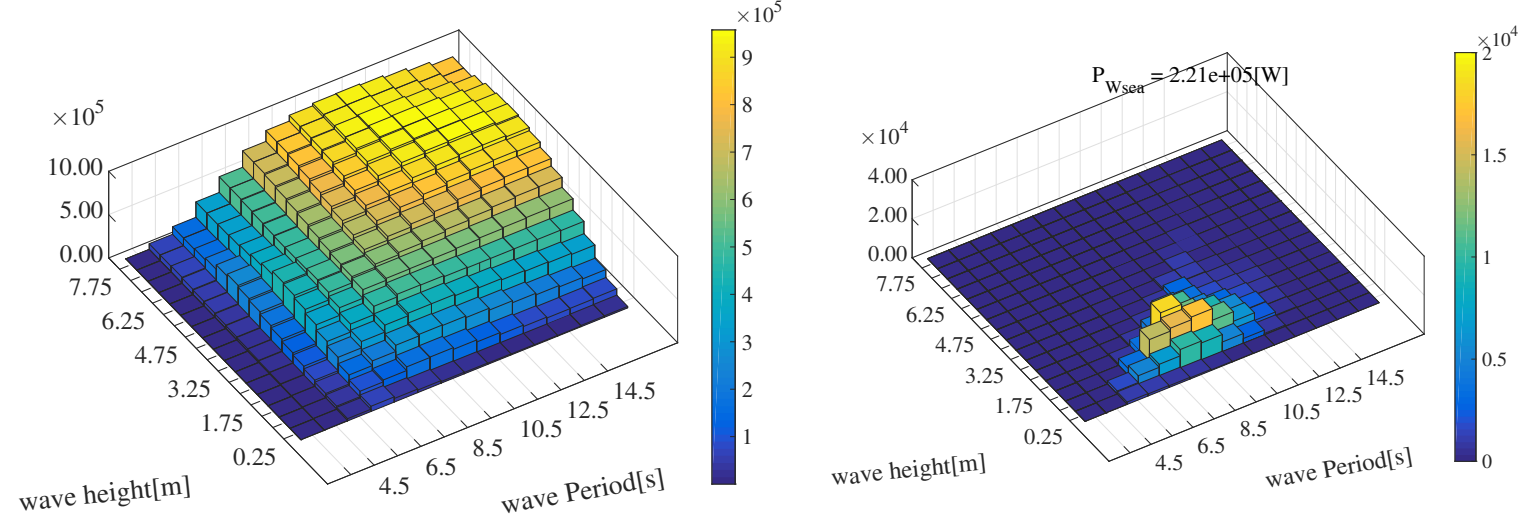

Figure 20. Arrange condition (Distribution map of electric power $\sigma$ on the left, and distribution map of electric power in a sea area $P \times \sigma$ on the right.)

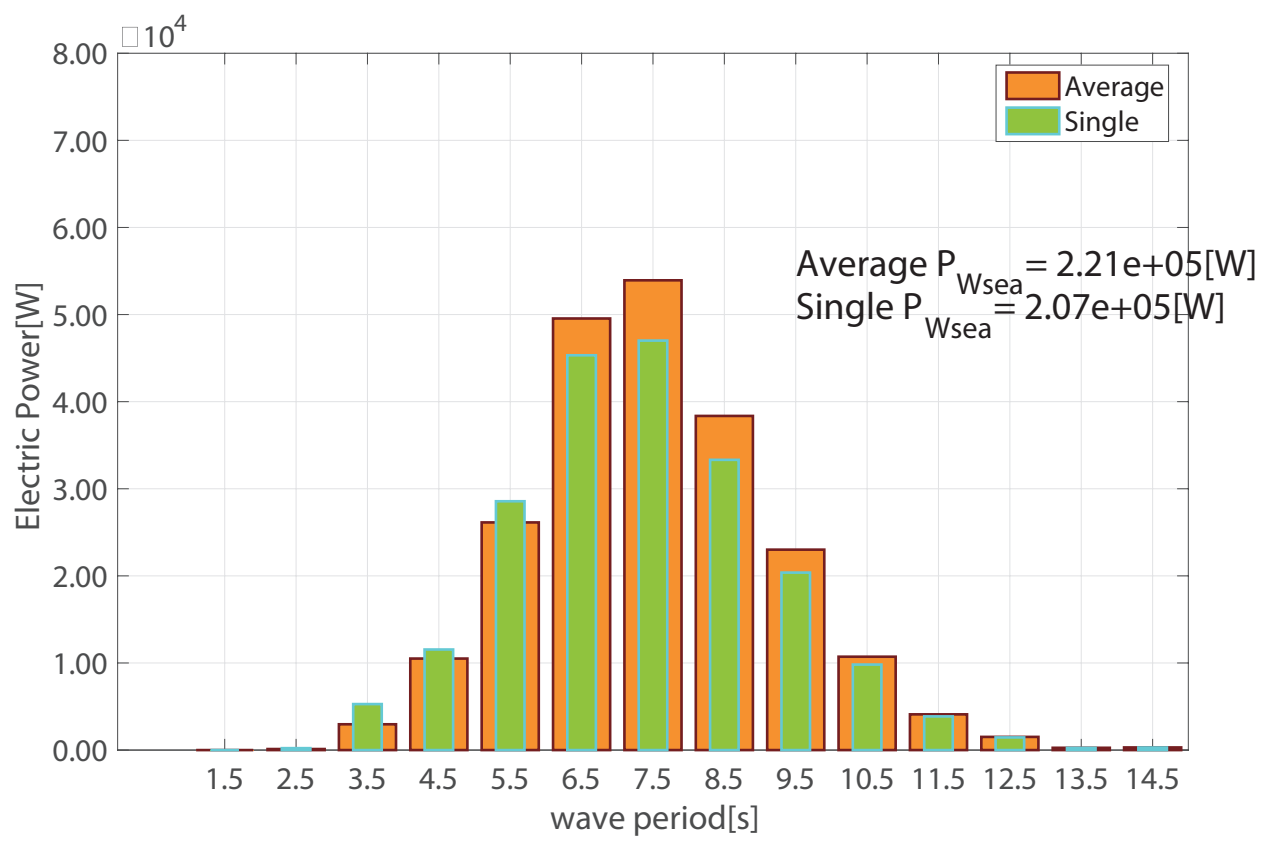

Figure 21. Electric power comparison in single condition and in arrange condition.

\section{Conclusions}

In general, the controlling force of WEC is optimized in single condition, and the same forces are used for each WEC in arrangement. Thus, the interference effect between the WECs is only considered in the transformation of wave energy to the motion of floating bodies, but the conversion from the motion to electric power is not optimized. In present paper, the interference effect of WECs is taken into account in motion calculation and motion-electric power conversion by appropriate arrangement for independently controlled WECs. The maximum electric power of multiple WECs is calculated and discussed in regular waves and real sea condition.

The following conclusions are obtained through the numerical consideration:

1. In arranged condition, the controlling force coefficient $C_{g}$ needs change independently for each wave energy converter following the wave period.

2. The generated electric power under independent control is better than that used the controlling parameters commonly in the array.

3. In a case study of three WECs, the average electric power controlled independently is $10 \%-20 \%$ bigger than in controlled commonly. 
4. The interference effect can be used to increase the electric power. In a case study of three WECs, the electrical power performance increases more than $10 \%-15 \%$ in straight arrangement and it reaches to more than $15 \%$ in triangle arrangement. The triangle arrangement is better than the straight arrangement for use interference effect.

5. Distance/Wave-Length determines the performance of WECs and the performance is changed cyclically along the parameter. It should be care that the interference effect appears even the distance of adjacent WEC is far.

6. WECs in appropriate arranging conditions could obtain much more electrical power than single's, and the appropriate arranging conditions must be match to the wave condition of the install sea area.

In the other our research it is suggested that the interference effect is increased by the number of consisted WECs. So, determining the parameters independently will be more important to the electric power maximization of huge number of WEC array. In that case, the knowledge obtained through this work will contribute much to the future work on it.

Author Contributions: Conceptualization, M.M.; Data curation, Q.L.; Formal analysis, Q.L.; Funding acquisition, M.M.; Investigation, Q.L.; Methodology, Q.L.; Project administration, M.M.; Software, Q.L.; Validation, Q.L. and S.K.; Visualization, S.K.; Writing—original draft, Q.L.; Writing—review \& editing, Q.L.

Funding: This research received no external funding.

Acknowledgments: This work is part of Linear-driving type Wave Energy Converter project supported by the New Energy and Industrial Technology Development Organization (NEDO). Highest gratitude is expressed to NEDO and research partners.

Conflicts of Interest: The authors declare no conflict of interest.

\section{References}

1. Drew, B.; Plummer, A.R.; Sahinkaya, M.N. A review of wave energy converter technology. Proc. Inst. Mech. Eng. Part A J. Power Energy 2009, 223, 887-902. [CrossRef]

2. Day, A.H.; Babarit, A.; Fontaine, A.; He, Y.-P.; Kraskowski, M.; Murai, M.; Penesis, I.; Salvatore, F.; Shin, H.-K. Hydrodynamic modelling of marine renewable energy devices: A state of the art review. Ocean Eng. 2015, 108, 46-69. [CrossRef]

3. Rezanejad, K.; Soares, C.G.; Lopez, I.; Carballo, R. Experimental and numerical investigation of the hydrodynamic performance of an oscillating water column wave energy converter. Renew. Energy 2017, 106, 1-16. [CrossRef]

4. Viviano, A.; Naty, S.; Foti, E. Scale effects in physical modelling of a generalized OWC. Ocean Eng. 2018, 162, 248-258. [CrossRef]

5. Naty, S.; Viviano, A.; Foti, E. Feaseability study of a WEC integrated in the port of Giardini Naxos, Italy. In Proceedings of the Coastal Engineering Conference, Antalya, Turkey, 17-20 November 2016.

6. Tedd, J.; Kofoed, J.P. Measurements of overtopping flow time series on the Wave Dragon, wave energy converter. Renew. Energy 2009, 34, 711-717. [CrossRef]

7. Zhang, X.; Lu, D.; Guo, F.; Gao, Y.; Sun, Y. The maximum wave energy conversion by two interconnected floaters: Effects of structural flexibility. Appl. Ocean Res. 2018, 71, 34-47. [CrossRef]

8. Nagulan, S.; Venkatesan, B.; Arunachalam, A. A review on front end conversion in ocean wave energy converters. Front. Energy 2015, 9, 297-310.

9. Hals, J.; Bjarte-Larsson, T.; Falnes, J. Optimum Reactive Control and Control by Latching of a Wave-Absorbing Semisubmerged Heaving Sphere. In Proceedings of the International Conference on Offshore Mechanics and Arctic Engineering OMAE, Oslo, Norway, 23-28 June 2002; Volume 4, pp. 415-423.

10. Nebel, P. Maximizing the Efficiency of Wave-Energy Plants Using Complex Conjugate Control. Proc. Inst. Mech. Eng. Part I J. Syst. Control. Eng. 1992, 206, 225-236. [CrossRef]

11. Hals, J.; Falnes, J.; Moan, T. Constrained Optimal Control of a Heaving Buoy Wave-Energy Converter. ASME J. Offshore Mech. Arct. Eng. 2011, 133, 011401. [CrossRef]

12. Hals, J.; Johannes, F.; Torgeir, M. A comparison of selected strategies for adaptive control of wave energy converters. J. Offshore Mech. Arct. Eng. 2011, 133, 031101. [CrossRef] 
13. Andrade, D.M.; Jaen, A.d.; Santana, A.G. Considering linear generator copper losses on model predictive control for a point absorber wave energy converter. Energy Convers. Manag. 2014, 78, 173-183. [CrossRef]

14. Taniguchi, T.; Umeda, J.; Fujiwara, T.; Goto, H.; Inoue, S. Experimental and Numerical study on Point Absorber Type Wave Energy Converter with Linear Generator. In Proceedings of the ASME 2017 36th International Conference on Ocean, Offshore and Arctic Engineering, Trondheim, Norway, 25-30 June 2017.

15. Zhang, X.; Tian, X.; Xiao, L.; Li, X.; Chen, L. Application of an adaptive bistable power capture mechanism to a point absorber wave energy converter. Appl. Energy 2018, 228, 450-467. [CrossRef]

16. Younesian, D.; Alam, M.R. Multi-stable mechanisms for high-efficiency and broadband ocean wave energy harvesting. Appl. Energy 2017, 197, 292-302. [CrossRef]

17. Zhang, X.; Yang, J. Power capture performance of an oscillating-body WEC with nonlinear snap through PTO systems in irregular waves. Appl. Ocean Res. 2015, 52, 261-273. [CrossRef]

18. Tetu, A.; Ferri, F.; Kramer, M.; Todalshaug, J. Physical and Mathematical Modeling of a Wave Energy Converter Equipped with a Negative Spring Mechanism for Phase Control. Energies 2018, 11, 2362. [CrossRef]

19. Troch, P.; Beels, C.; De Rouck, J.; De Backer, G. Wake Effects Behind a Farm of Wave Energy Converters for Irregular Long-Crested and Short-Crested Waves. In Proceedings of the International Conference on Coastal Engineering, Shanghai, China, 30 June-5 July 2010.

20. Folley, M.; Babarit, A.; O'f Boyle, L.; Child, B.; Forehand, D.; Silverthorne, K.; Spinneken, J.; Stratigaki, V.; Troch, P. A Review of Numerical Modeling of Wave Energy Converter Arrays. In Proceedings of the 31st International Conference on Offshore Mechanics \& Arctic Engineering, Rio de Janeiro, Brazil, 10-15 June 2012.

21. Li, Y.; Yu, Y.-H. A synthesis of numerical methods for modeling wave energy converter-point absorbers. Renew. Sustain. Energy Rev. 2012, 16, 4352-4364. [CrossRef]

22. Borgarino, B.; Babarit, A.; Ferrant, P. Impact of wave interactions effects on energy absorption in large arrays of wave energy converters. Ocean Eng. 2012, 41, 79-88. [CrossRef]

23. Stratigaki, V.; Troch, P.; Stallard, T.; Forehand, D.; Kofoed, J.P.; Folley, M.; Benoit, M.; Babarit, A.; Kirkegaard, J. Wave Basin Experiments with Large Wave Energy Converter Arrays to Study Interactions between the Converters and Effects on Other Users in the Sea and the Coastal Area. Energies 2014, 7, 701-734. [CrossRef]

24. Leijon, M.; Bernhoff, H.; Agren, O.; Isberg, J.; Sundberg, J.; Berg, M.; Karlsson, K.E.; Wolfbrandt, A. Multiphysics Simulation of Wave Energy to Electric Energy Conversion by Permanent Magnet Linear Generator. IEEE Trans. Energy Convers. 2015, 20, 219-224 . [CrossRef]

25. Kim, W.D. On the Harmonic Oscillation of a Rigid Body on a Free Surface. J. Fluid Mech. 1965, 21, 427-451. [CrossRef]

26. Garrison, C.J.; Rao, V.S. Interaction of Waves with Submerged Objects. J. Waterways Harb. Coast. Eng. Division 1971, 811, 259-276.

27. Faltinsen, O.M.; Michelson, F.C. Motions of Large Structures in Waves at Zero Froude Number. In Proceedings of the International Symposium on the Dynamics of Marine Vehicles and Structures in Waves, London, UK, 1-5 April 1974; pp. 91-106.

28. Van Oortmerson, G. The motion of a ship in Shallow Water. Ocean Eng. 1976, 3, 221-255. [CrossRef]

29. Design of Ocean Systems-Ocean Wave Environment, MIT Open Course Ware. 7 March 2011. Available online: https:/ / ocw.mit.edu/courses / mechanical-engineering/2--019-design-of-ocean-systems-spring2011/lecture-notes/MIT_019S11_OWE.pdf (accessed on 23 October 2018).

30. Walter, H. Michl: Sea Spectra Revisited. Mar. Technol. 1999, 36, $211-227$.

31. Statistical Database of Winds and Waves around Japan, National Maritime Research Institute. Available online: https:/ /www.nmri.go.jp/wwjapan/namikaze_main_e.html (accessed on 23 October 2018).

(c) 2018 by the authors. Licensee MDPI, Basel, Switzerland. This article is an open access article distributed under the terms and conditions of the Creative Commons Attribution (CC BY) license (http://creativecommons.org/licenses/by/4.0/). 